\author{
Military Technical College \\ Kobry El-Kobbah, \\ Cairo, Egypt
}

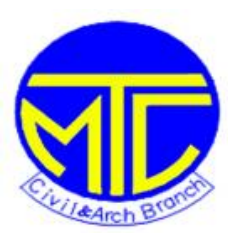

$9^{\text {th }}$ International Conference on Civil and Architecture Engineering ICCAE-9-2012

\title{
Simulation of Composite Steel Building Exposed to Fire
}

\begin{abstract}
Sanad, Abdel Moniem
Abstract

The behaviour of composite steel structures during fire is a fundamental criterion for the global stability and durability of these structures. Following several fire disasters, the assessment of structures stability and behaviour of individual elements have been the focus of many research projects in fire safety over the last two decades. Full scale experimental works and finite element modelling developed by Sanad et al. were carried to understand the effect of fire on composite buildings. In full scale buildings, slabs, beams and col umns behave in different ways and depend on the strength, duration and variation of heating regime with time and space. Recent researches showed that the behaviour of indeterminate beams under fire is dominated by thermal expansion and changes drastically from its behaviour under ambient condition. However, in composite structures, the reinforced concrete slab acts together with steel beams to provide the needed bending capacity for carrying the applied loads. During real fire, the different conductivity of concrete and steel creates huge difference of temperature between the two elements. Their behaviour at high temperature varies from ambient conditions and the role of composite action in transferring the applied loads changes accordingly. In this paper, a numerical model for composite floor during fire is developed using finite element program ABAQUS. It is validated against full scale fire test, with the ultimate objective of investigating the behaviour and contribution of steel beam and concrete slab to the global stability of the composite structure during fire. Both the obtained numerical and experimental results are in good agreement and the model proposed in this paper can predict with acceptable accuracy the global behaviour of the structure under fi re.
\end{abstract}

\section{Keywords}

Finite Element Analysis, Real Fire Conditions, Composite floor, Reinforce Concrete Slab, Steel Joist.

\section{Introduction}

Over the last two decades, many research programs have studied the effect of fire on steel frame structures. When a compartment in a large building is exposed to a severe fire, the behaviour of the heated zone is strongly affected by the surrounding parts of the structure that remain cold, stiff and strong. The interactions between the heated zone, which is expanding

* Associate Professor and Chairman of Construction and Building Eng. Dept., Arab Academy for Science and Technology and Maritime Transport, Cairo 
and losing strength, and the surrounding cold structure produce several different effects that are difficult to present in the conventional manner, where each member is proportioned as isolated, but subject to stress resultants found from a global analysis. Thus, current practice, based on the behaviour of an isolated element in a test furnace, seriously misrepresents the behaviour of elements of the complete redundant floor system. To achieve a reali stic condition of fire, British Steel [2] carried out several full scale fire tests in Cardington. In order to understand the behaviour of real buildings under fire condition, numerical calculations have become unavoidable. The Finite Element Method (FEM) is now the principal tool for simulating the tests and understanding the local and global structural behaviour. After validating the numerical models with the experimental results, it can be used to obtain information about quantities that cannot be measured, such as internal forces and moments in a structural element. If the numerical model predictions match the measured responses on those items, which can be measured, then it is reasonable to infer that other parts of the prediction are also realistic components of the complete behaviour. Thus, the calculation of the structure during fire can be used to deduce many features of the response that cannot be deduced in any other way. Several models have been developed for each test with different degrees of precision and simplification. Each of them has its advantages. Among the first models are the one developed by Wang et $a l$. [21] which was a 2D model and produced useful conclusions on the critical role of steel columns exposed to fire. A further theoretical study by Wang [22] indicated the importance of tensile membrane action in maintaining the robustness of composite RC slabs. Rose et al. [11 and 13 ] published one of the first 3D models of the Cardington tests, which showed a good match betw een predicted and test deflections for the Restrained Beam test, the Plane Frame test and the B ritish Steel Corner test [2]. Some of the models have been developed using pre-defined shell elements for the composite slab for the corner fire test [6]. The models were in agreement with the experimental results, however in this type of models [7], the structural analysis of slab behaviour and the interpretation of results become very sophisticated and difficult to implement in design code for practicing engineers. An alternative simpler model for composite floor is proposed in this paper using the finite element program ABAQUS [1]. It is based on the simulation of slabs by a grillage model with different behaviour in the two directions. This model has been used successfully to simulate and analyse the behaviour of the first test [16], and now is developed further to simulate the corner test. It has the advantages of providing a realistic simulation of the full scale tests and distinguishes clearly the behaviour of floor in the 2D at different locations. The Corner test is described in details in this paper and the model developed is validated against the full scale measurement.

\section{Geometric description}

\section{$\underline{\text { Layout }}$}

The fire test concerns a compartment of approximately $80 \mathrm{~m} 2$, built on the first floor in one corner of the 8 story composite building shown in Fig ure 1 [11]. To achieve the required level of thermal loading (around $1000^{\circ} \mathrm{C}$ ), a real fire was created, with a fire loading of $45 \mathrm{~kg}$ of wood $/ \mathrm{m} 2$ and the ventilation was provided by an adjustable $7 \mathrm{~m}$ wide 


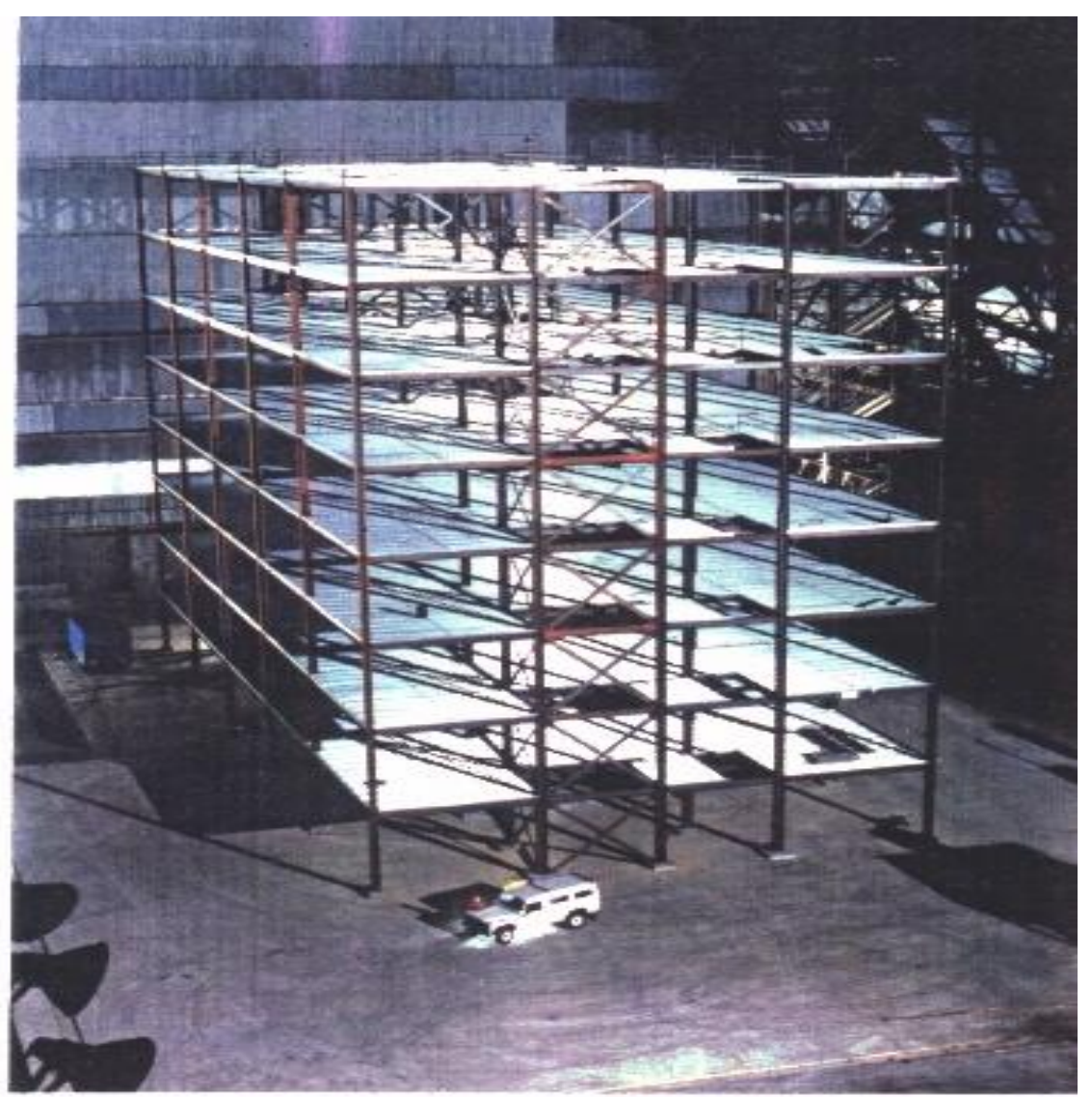

Figure 1 - Cardington full scale testing building [11]

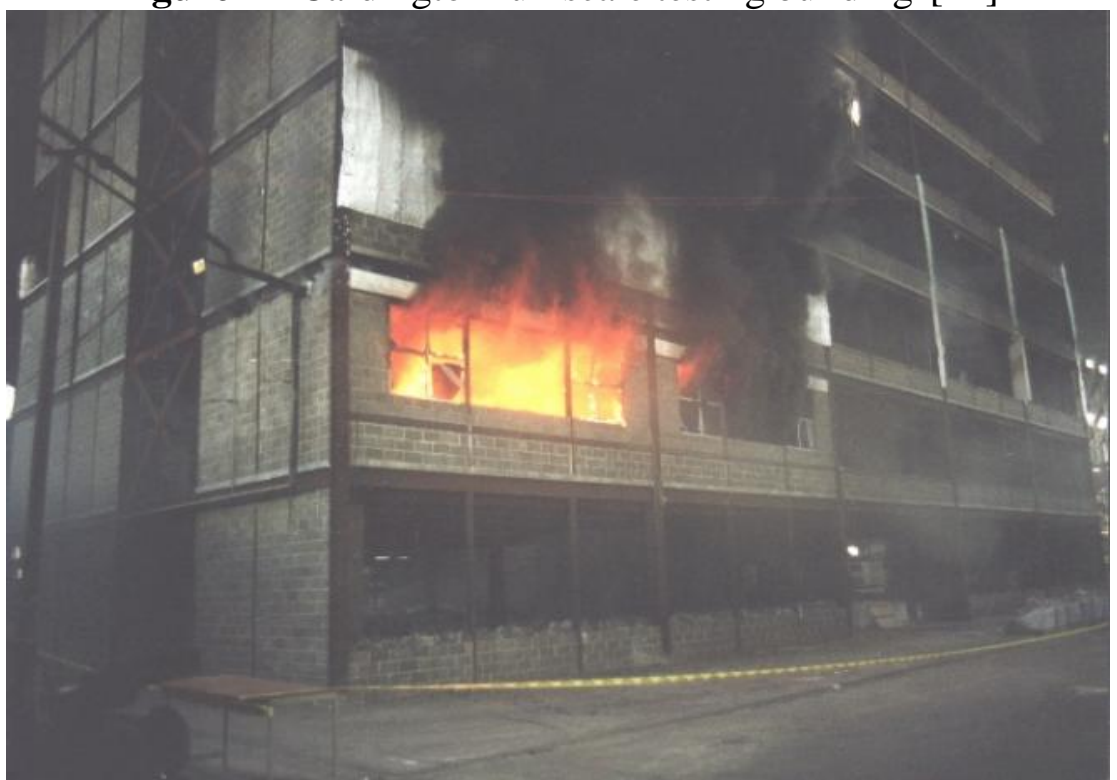

Figure 2 - Corner fire test on the second floor of the building [11]

opening as shown in Figure 2. The tested floor contains 4 unprotected beams and 2 protected edge beams. All secondary composite beams are equally spaced and have $9 \mathrm{~m}$ span connected semi-rigidly to columns or to primary beams. The heated primary beam has a length of $6 \mathrm{~m}$. 
All steel columns were protected along their full height. The composite profiled RC deck slab has a span of $3 \mathrm{~m}$ between secondary beams [2].

\section{Proposed Finite element mesh}

Figure 3 shows the proposed finite element model, developed by the author for fire Test 3 . The area affected by the fire is indicated by dashed lines. In the direction of the secondary composite beams (longitudinal), the model starts from the corner of the structure, covers the heated compartment and extends to the end of the span beyond the compartment to include the membrane forces expected to develop during the fire. In the transverse direction (direction parallel to the slab ribs), the model starts from the edge of the building, covers the heated compartment and extends to the centre line of the building for the same reason. In the proposed model, each structural steel member is idealized by an appropriate beam element .

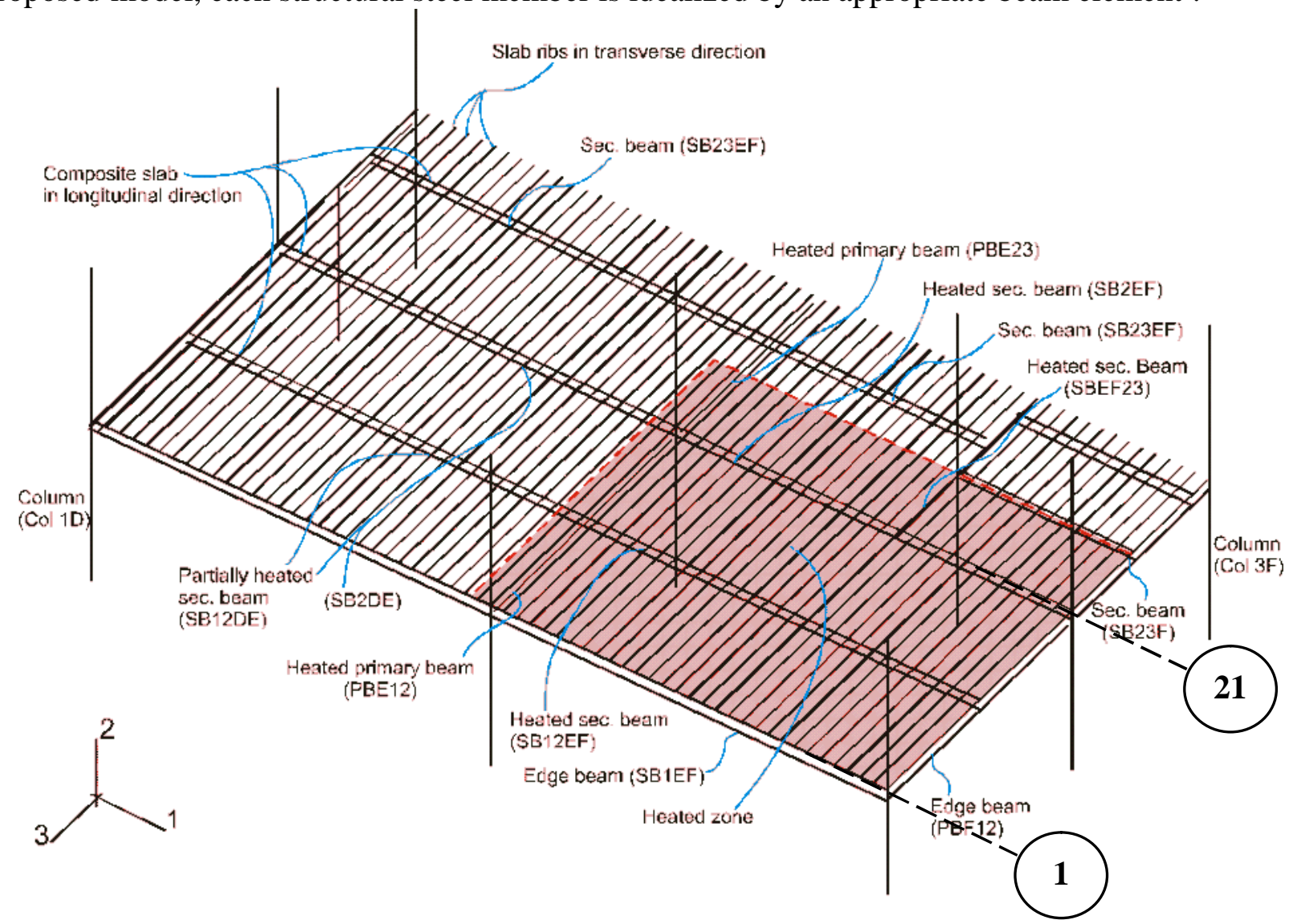

Figure 3 - Finite Element mesh for fire Test 3 [19]

Figure 3 shows the typical cross-section of the steel members and Table 1 gives the dimensions of the primary and secondary joists respectively. The centroid of the secondary joists is located $152.5 \mathrm{~mm}$ below the reference vertical co-ordinate of the joist's top flange. The centroid of the primary and edge joists is located $178 \mathrm{~mm}$ below the reference level. The column is modelled using similar beam elements. 


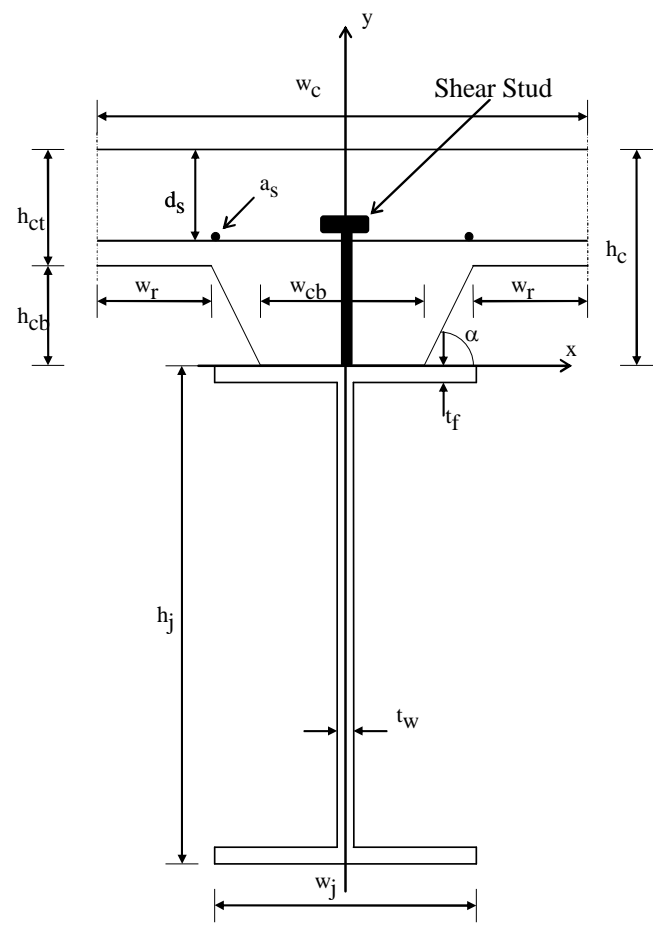

Figure 4 - Typical composite section

Table 1 - Dimensions of the steel members

\begin{tabular}{|c|c|c|c|c|}
\hline & $h_{j}(\mathrm{~mm})$ & $\mathrm{w}_{\mathrm{j}}(\mathrm{mm})$ & $\mathrm{t}_{\mathrm{f}}(\mathrm{mm})$ & $\mathrm{t}_{\mathrm{w}}(\mathrm{mm})$ \\
\hline Primary \& Edge beams (H) & $\mathbf{3 5 5 . 6}$ & $\mathbf{1 7 1 . 5}$ & $\mathbf{1 1 . 5}$ & $\mathbf{7 . 3}$ \\
\hline Secondary beams (L) & $\mathbf{3 0 3 . 8}$ & $\mathbf{1 5 1 . 9}$ & $\mathbf{1 0 . 2}$ & $\mathbf{6 . 1}$ \\
\hline
\end{tabular}

Table 2 - Dimensions of slab sections

\begin{tabular}{|c|c|c|c|c|c|c|c|c|}
\hline & & $\mathrm{W}_{\mathrm{c}}(\mathrm{mm})$ & $\mathrm{W}_{\mathrm{cb}}(\mathrm{mm})$ & $\mathrm{h}_{\mathrm{ct}}(\mathrm{mm})$ & $\mathrm{h}_{\mathrm{cb}}(\mathrm{mm})$ & $\alpha\left(^{\circ}\right)$ & $\mathrm{a}_{\mathrm{s}}(\mathrm{mm})$ & $\mathrm{d}_{\mathrm{s}}(\mathrm{mm})$ \\
\hline Slab & in & 300 & 136 & 70 & 60 & 65 & 42.6 & 55 \\
\hline Slab & in & 2250 & - & 70 & - & - & 319.5 & 55 \\
\hline
\end{tabular}

The slab behaviour is modelled by a grillage type idealization using beam elements to represent the slab behaviour in both the longitudinal and transverse directions. In the longitudinal direction $(\mathrm{X})$, the slab element has a rectangular section with $70 \mathrm{~mm}$ depth and an effective width equal to $2250 \mathrm{~mm}$, calculated according to the Eurocode 4 [5] for a simply supported beam case. In the transverse direction (Y), slab elements have a trapezoidal shape and the geometry of the concrete section in this direction is shown in Figure 5. The thickness 
of the used steel deck is $9 \mathrm{~mm}$ and a secondary reinforcement steel mesh of $142 \mathrm{~mm}^{2}$ was provided. Table 2 shows the dimensions of the used concrete section in both directions.

\section{Behaviour steel members exposed to high temperature}

For steel structures exposed to high temperature the relationship between stress and strain changes considerably. At increased temperature, the steel properties degrade and its capacity to deform increases which is measured by the reduction of the Young's modulus. In the proposed FE model, the relation between the stress and the strain under high temperature is defined according to Eurocode 3 [4]. For all steel members, the classic linear beam element applying the hypothesis of plane surface remains plane is used. Each point on the cross section, along each member, follows the stress -strain relationship as a function of the point's temperature. This takes into consideration the variable temperature profile applied across the section and the corresponding material properties during different stages of the fire. The connections between different steel members (beam to column connection and beam $t$ o beam connection) are modelled by pin connections where boundary conditions are imposed on the relative displacement of the joining elements.

\section{$\underline{\text { RC Slab modelling }}$}

The behaviour of concrete is characterized by material property degradation with increased temperature. The stress-strain relationship is then defined according to Eurocode 2 [3]. For the RC slab, more complex behaviour has to be modelled. The different behaviour of concrete in tension and compression, the orthotropic behaviour due to the reinforcing mesh and the decking steel and the development of membrane action need to be considered in order to provide a realistic representation of the RC slab behaviour. In the numerical model developed in this paper, the concrete modelling is based on the global behaviour of the concrete section, considering the above factors. The RC slab is modelled by two sets of beam elements running parallel and perpendicular to the secondary beams. In each direction, the beam elements have a pre-defined force-strain and moment-curvature relationships. These relationships are calculated based on the geometry and the material properties of the composite section in each direction and taking into account the variable temperature over the same sectio $\mathrm{n}$ and the corresponding material properties as presented by O'Connor et al. [10].

\section{Connections between members}

In this paper, the beam models for the longitudinal action of the $\mathrm{RC}$ deck slabs are connected to the steel joist using rigid beam connection. This provides a rigid beam between two nodes to constrain the displacement and rotation of the slab's node to the displacement and rotation of the joist's node, corresponding to the presence of a rigid beam between the two nodes. The vertical separation of the joist centroid and the longitudinal slab is properly modelled. The centroid of the longitudinal slab is taken as $35 \mathrm{~mm}$ below the slab surface and the thickness of the longitudinal RC slab is $70 \mathrm{~mm}$. According to Eurocode 4 [5], the effective width of the longitudinal slab was taken as $2250 \mathrm{~mm}$ throughout the length of the internal secondary beams and half this width for the edge beams. 
For the transverse action of the RC slab the compatibility of deflection with the secondar $\mathrm{y}$ steel joists was assured using pin connection at the crossing points to allow large deflection and large rotation in the developed model. The vertical separation between centroid of the secondary joists and the transverse slab is properly represented, wi the centroid of the transverse ribs taken as $55 \mathrm{~mm}$ below the slab surface. All secondary beams (joists) have a composite slab connected to them.

For the steel connection, the end of the each secondary beam (joist) is connected to the primary beams (joists), in case of beam to beam connection. Each primary beam has a composite slab connected to it in a similar way as for the secondary joists. In case of beam to column connections, the secondary or primary beams are connected to the column at the level of their centre lines.

\section{Proposed boundary conditions for the tested steel building}

The columns are completely fixed at the bottom ends and free to displace vertically at the top ends. Column rotation about the vertical axis is fixed at the level of the connec tion with the beams. For the steel joists, the rotations about the joist axis and the vertical axis are restrained. Parallel to the primary beams, the interaction with the surrounding structure at the internal limit of the model is assumed to be symmetrical condition where longitudinal displacements and rotations about transverse horizontal axis are fixed for the primary joist. In the other direction, the interaction with the surrounding structure at the internal limit of the model is also defined assuming symmetrical condition where the transverse displacements and rotations about the longitudinal axis are restrained at the slab end.

Each longitudinal RC slab is connected to a secondary steel joist, thus has the same boundary conditions as the joist below it (symmetrical conditions at mid-span). The longitudinal slab above each secondary joist is connected to the longitudinal slab over the adjacent joist in case of beam to column connection. The longitudinal slab above each secondary joist is connected to the slab over the primary beam in case of beam to beam connection. For the transverse slab, the slab is treated as translationally and rotationally continuous over the secondary beams. The rotations about vertical and lateral directions are fixed at the fa $r$ end points, which are fixed against the horizontal displacement in the direction of the rib axis, and the horizontal displacement normal to the rib axis. These points are free to move vertically (perpendicular to the plane of the slab).

\section{Calculation for the test loads}

The self-weight of the composite structure and the live load applied during the test are combined to give an imposed floor load of $5.48 \mathrm{kN} / \mathrm{m}^{2}$ [11]. In the numerical model, a distributed load of $5.48 \mathrm{kPa}$ is applied to the slab by means of the uniformly distributed loads on the ribs. For each rib with $30 \mathrm{~cm}$ width, the applied load is $1.644 \mathrm{kN} / \mathrm{m}$. This is maintained at constant value throughout the thermal loading process. Non -linear geometric and material effects were modelled based on the large deformation theory using the Newton-Raphson method. 


\section{Thermal load}

The effect of fire on the structure is modelled by increasing the temperature linearly over 2 steps, from ambient temperature to the maximum temperature reached for each member respectively. The thermal effect on the structure was modelled by considering both, the expansion of each element and the thermal gradient across its section. These two factors are applied to the reinforced concrete slab as well as the ste el joists. Thermal loading is applied only to the compartment heated zone and outside it according to the test measurements. It is applied by defining the final temperature over each joist and assuming a linear variation from the initial temperature $\left(0^{\circ} \mathrm{C}\right)$ to the final temperature. Each steel joist has a centroid constant temperature along its total length and has a vertical variation in temperature across its section. The vertical variations in temperature are included as a direct input following the test measurements. Temperature gradients are modelled in both the slab and the joists. For the beam finite elements adopted here, the temperatures are defined at five points across the joists section (the centroid and 2 points in each flange). The extreme fibre temperature of the lower flange of the secondary joist on grid line 2 [Figure 3] is used here as the reference temperature (RLFT). It is the average of the input temperature values for the 2 points on the lower flange.

For the slab, only the zone within the compartment is heated. The parts of the slab which lie outside the compartment zone are treated as remaining at ambient temperature at all times. The heating effects for the slab (membrane and gradient values) are applied both to the longitudinal slab and the transverse slab models separately. The temperatures of all points in the slab which lie within the compartment are treated as equal at a given height within the slab. Each rib has a constant temperature ov er its heated length and is considered to be at ambient temperature outside the furnace. It may be noted here that the temperature applied to the slab is the mean temperature acting on its geometric centre and the gradient across its thickness is the mean gradient deduced from the temperature distribution calculated separately for the longitudinal and the transverse directions. Figure 6 shows an example of the mean temperature measured during the fire for the slab and the beams at different locations inside the fire compartment. In the model, the temperature varies from one beam to another according to the measured temperatures after 75minutes. In this report, the default temperature chosen to describe the different phenomena during the test is the temperatu re of the lower flange of the beam on grid line 2 [Figure 3]. 


\section{Structural Element Temperatures in Test 3}

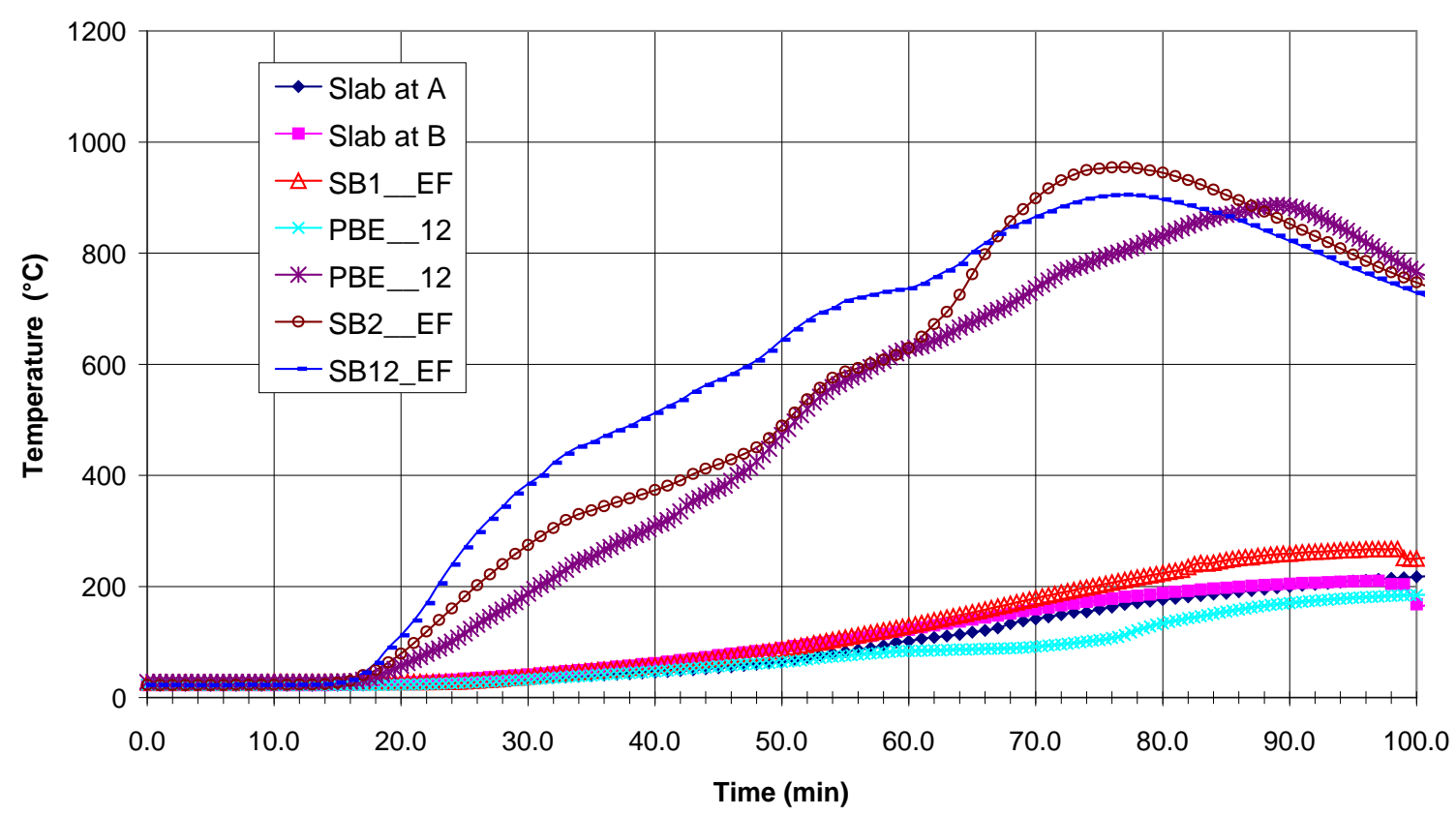

Figure 5 - Measured temperatures for the tested joists and slab inside the fire compartment

For the steel elements in the numerical model, the time lag between the lower flange temperature (LFT) and the upper flange temperature (UFT) is represented by assuming a linear increase in the difference between the LFT and the UFT. Table 3 shows the temperature profile applied for each of the steel members with initial temperature starting from 0 at ambient temperature.

Table 3 - Thermal loading for the steel elements

\begin{tabular}{|c|c|c|c|c|}
\hline & \multicolumn{2}{|c|}{ Step 1 } & \multicolumn{2}{c|}{ Step 2 } \\
\hline Steel members & LFT & UFT & LFT & UFT \\
\hline SB1_EF (protected) & $120^{\circ} \mathrm{C}$ & $96^{\circ} \mathrm{C}$ & $270^{\circ} \mathrm{C}$ & $\begin{array}{c}216^{\circ} \\
\mathrm{C}\end{array}$ \\
\hline SB12_EF & $690^{\circ} \mathrm{C}$ & $\begin{array}{c}552^{\circ} \\
\mathrm{C}\end{array}$ & $760^{\circ} \mathrm{C}$ & $\begin{array}{c}950^{\circ} \\
\mathrm{C}\end{array}$ \\
\hline SB2_EF & $\begin{array}{c}690^{\circ} \mathrm{C} \\
(\mathrm{RLET})\end{array}$ & $\begin{array}{c}552^{\circ} \\
\mathrm{C}\end{array}$ & $1000^{\circ} \mathrm{C}(\mathrm{RLFT})$ & $\begin{array}{c}800^{\circ} \\
\mathrm{C}\end{array}$ \\
\hline PBE_12 & $600^{\circ} \mathrm{C}$ & $\begin{array}{c}480^{\circ} \\
\mathrm{C}\end{array}$ & $800^{\circ} \mathrm{C}$ & $\begin{array}{c}720^{\circ} \\
\mathrm{C}\end{array}$ \\
\hline PBF_12 (protected) & $120^{\circ} \mathrm{C}$ & $96^{\circ} \mathrm{C}$ & $120^{\circ} \mathrm{C}$ & $\begin{array}{c}216^{\circ} \\
\mathrm{C}\end{array}$ \\
\hline
\end{tabular}

The relationship between the refe rence lower flange temperature $(\mathrm{LFT}=\mathrm{T} 1)$ and the slab centroidal temperature $(\mathrm{SCT}=\mathrm{T} 2)$ is characterized by a bi-linear relationship with the 
following co-ordinates (T1, T2): $(0,0),(200,690)$ and $(400,1000)$ respectively. The relationship between the lower flange temperature $(\mathrm{LFT}=\mathrm{T} 1)$ and the slab temperature gradient (SGT $=$ DT3) is characterized by a bi-linear relationship with the following co ordinates (T1,DT3): $(0,0),(1000,3)$ (i.e. the centroidal temperature and the gradient are arranged to give the top surface of the transversal slab rising to 205 degrees at the end of the test, whilst the lower surface reaches $595^{\circ} \mathrm{C}$ when the reference lower flange temperature reaches $1000^{\circ}$ ).

Table 4 gives the temperature evolution during the 2 simulation steps for the slab in the longitudinal and transverse directions. It is to be noticed here that the slab temperature was higher than in the test $\left(400^{\circ} \mathrm{C}\right.$ instead of $\left.300^{\circ} \mathrm{C}\right)$. In fact the mean uncertainty over the right values for the temperature acting over the slab thickness led to assume a higher value in the numerical model to achieve the correct deformed shape.

Table 4 - Thermal loading for the slab elements

\begin{tabular}{|l|c|c|c|c|}
\hline & \multicolumn{2}{|c|}{ Step 1 } & \multicolumn{2}{c|}{ Step 2 } \\
\hline \multicolumn{1}{|c|}{ Tested Slab } & Centroid & Gradient & Centroid & Gradient \\
\hline Slab in transverse direction & $200^{\circ} \mathrm{C}$ & $3^{\circ} \mathrm{C}$ & $400^{\circ} \mathrm{C}$ & $3^{\circ} \mathrm{C}$ \\
\hline Composite slab (Primary beams) & $195^{\circ} \mathrm{C}$ & $2^{\circ} \mathrm{C}$ & $390^{\circ} \mathrm{C}$ & $2^{\circ} \mathrm{C}$ \\
\hline Composite slab (Secondary beams) & $200^{\circ} \mathrm{C}$ & $3^{\circ} \mathrm{C}$ & $400^{\circ} \mathrm{C}$ & $3^{\circ} \mathrm{C}$ \\
\hline Edge composite slab & $100^{\circ} \mathrm{C}$ & $2^{\circ} \mathrm{C}$ & $260^{\circ} \mathrm{C}$ & $2^{\circ} \mathrm{C}$ \\
\hline
\end{tabular}

\section{Comparison with Experimental Measurements}

\section{Deflection of primary beams}

Many measurements were taken over all the heated joists. The maximum measured deflection for each joist was at mid-span. Here the numerical prediction of the maximum deflection is compared with the experimental results. First comparison is for the heated primary beam on grid line-E. The first measurement point is located on the bottom flange of the beam at mid span. Figure 7 shows the relation between the deflection of the beam at mid -span and the reference temperature of the lower flange of the hottest joist (SB2_EF) at mid-span. The negative sign for the deflection indicates a vertical displacement downward. Both numerical and experimental results show that the deflection increases with temperature and the experimental measurements show a non-linear relationship with three major patterns. First, from 0 to $600^{\circ} \mathrm{C}$ (RLFT) with a non linear increase of deflection against temperature, then from $600^{\circ} \mathrm{C}$ to $900^{\circ} \mathrm{C}$ with an overall linear pattern characterized by a flatter slope, then a final stage from $900^{\circ} \mathrm{C}$ to $1000^{\circ} \mathrm{C}$ where the deflection increases rapidly against the temperature. In this last phase, the rapid increase in deflection is due to a rapid increase in the 
slab temperature, which combined with the steel joists temperature pr oducing the overall thermal regime applied to the composite slab.

\section{Test 3 Joist deflection under increasing temperature}

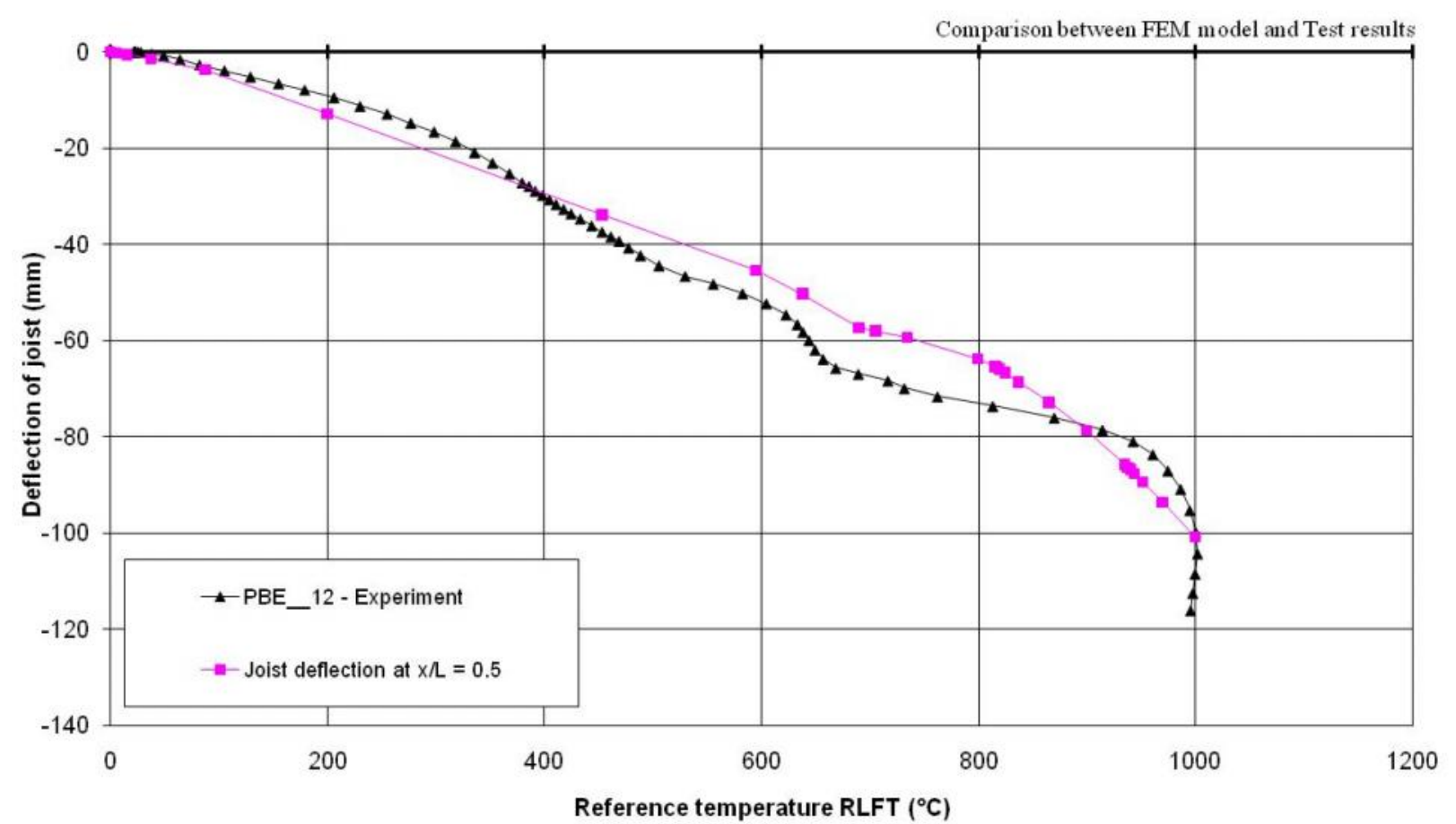

Figure 6 - Deflection of the heated primary beam at mid span

In the developed FE model, two main patterns can be distinguished, first from 0 to $690^{\circ} \mathrm{C}$ where the deflection increases with nearly a linear relationship, followed by the second phase up to $1000^{\circ} \mathrm{C}$ in which the relation becomes non-linear with a rapid increase of the deflections against the time. The deflection predicted by the numerical model reaches the same final value of $100 \mathrm{~mm}$ at $1000^{\circ} \mathrm{C}$, with close values of the experiment results all the way during the fire. The maximum difference between the model and the test is approximately $10 \mathrm{~mm}$ and is recorded near $700^{\circ} \mathrm{C}$. The difference between the model and the test can be attributed to the approximated temperatures applied over mainly the slab. It is to be noticed here that the measurement of temperature over the slab was insufficient to give a complete spatial distribution (only 4 locations over the $80 \mathrm{~m}^{2}$ of the heated zone). 


\section{Test 3 Joist deflection under increasing temperature}

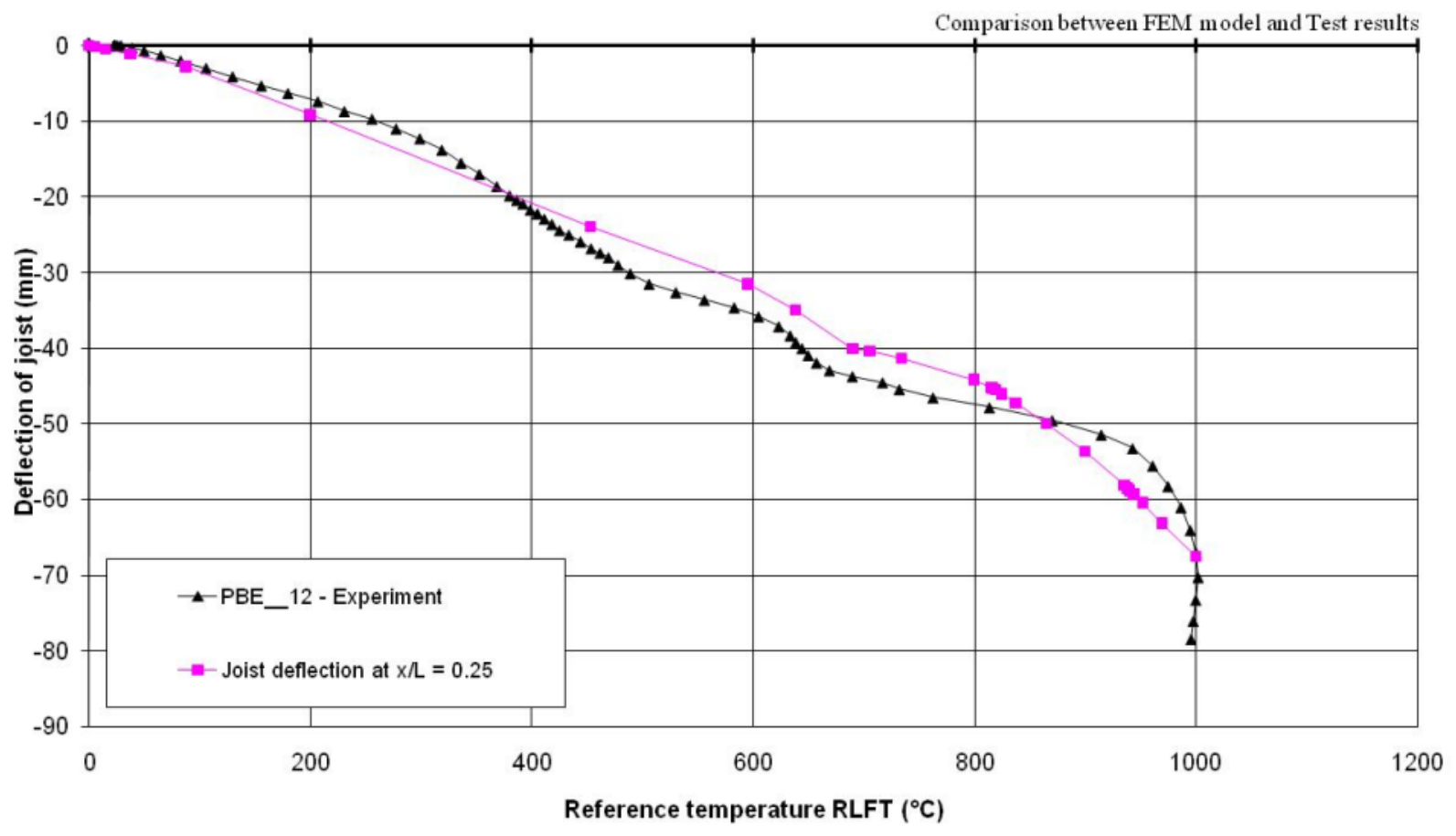

Figure 7 - Deflection of the heated primary beam at $x / L=25 \%$

To ensure that the deflected shape of the beam is coherent between the developed model and the experiment, the deflection at a second point along the primary beam is compared in Figure 8. The point is located on the lower flange of the beam at $1.5 \mathrm{~m}$ from the column (Figure 3 ). It can be observed that the same patterns as at mid-span in both the experiment and the numerical model and the values predicted are close to that measured, indicating that for the primary beam the model is predicting the correct deflections. It is to be noticed that the shape of the deflection-temperature curve is governed by the deflection of the beam related to the reference temperature chosen; the last steep increase in the test measurements between $900^{\circ} \mathrm{C}$ and $1000^{\circ} \mathrm{C}$ is really due to the relative rate of heating of the whole structure (slab and joists) against the reference joist rate of heating only. At this final stage, the ref erence joist had a very low temperature rate of heating which reached $1000^{\circ} \mathrm{C}$ then started to decrease again, while in the numerical model the calculation ends at the maximum temperature, this explains the difference of shape between the two curves (test ag ainst model).

\section{Deflection of secondary beams}

Here the numerical prediction of the maximum deflection is compared with the experimental result. First comparison is for different secondary beams. The first point of comparison here is located on the secondary joist on grid line 2. This joist was connected to a column at each end and the maximum deflection was obtained at mid-span. In Figure 9, it can be seen that the behaviour is mainly divided into two part, the first from 0 to $690^{\circ} \mathrm{C}$ the relationship is 
approximately linear, from $690^{\circ} \mathrm{C}$ to $1000^{\circ} \mathrm{C}$ a steep increase of deflection against the joist temperature.

\section{Test 3 Joist deflection under increasing temperature}

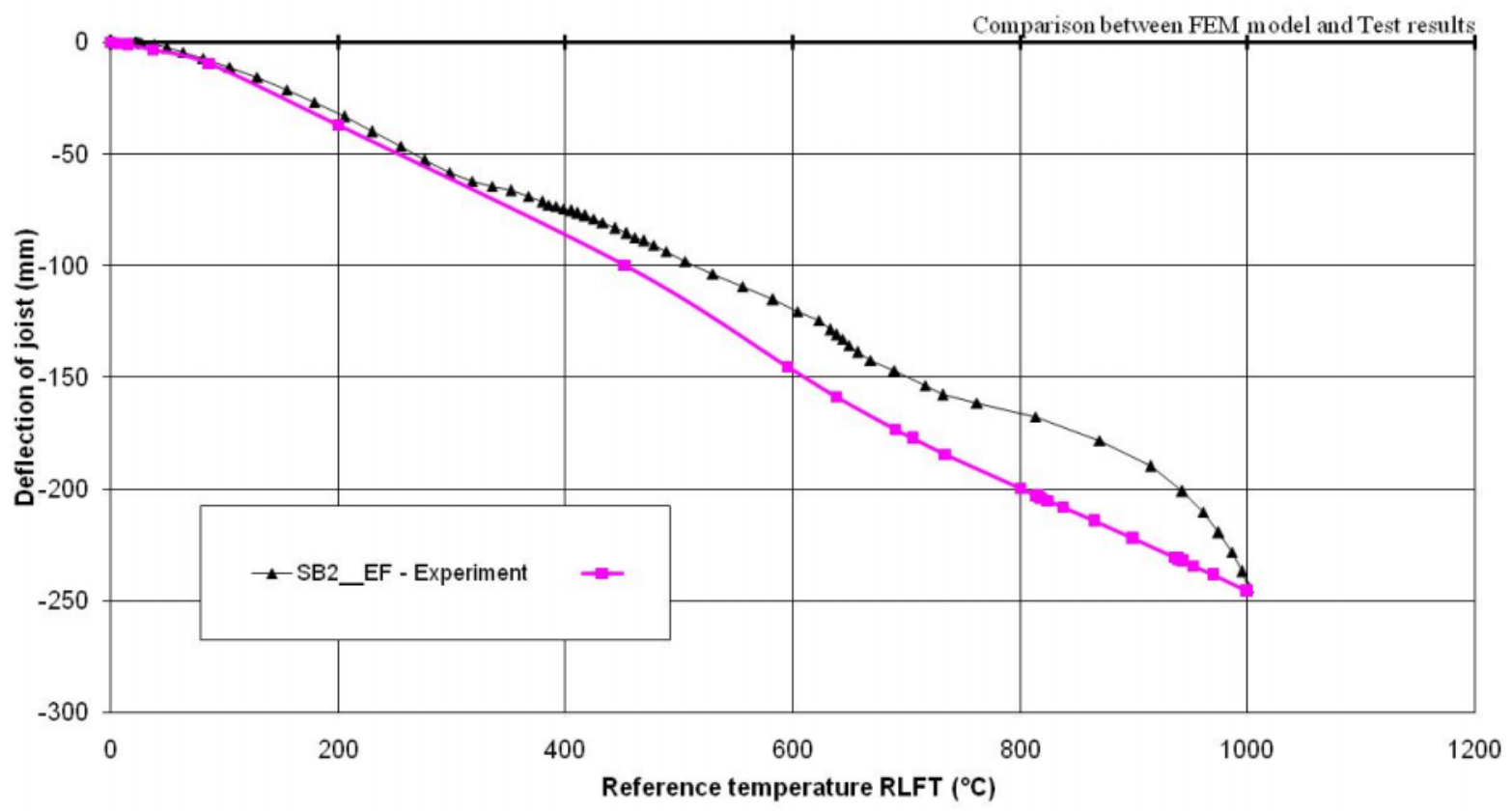

Figure 8 - Mid-span deflection of the heated secondary beam on grid line 2

The second part of the behaviour is identical to that of the last pattern observed for the primary beam and is mainly due to the temperature regime applied to the structure at the end of the fire. The numerical predications are in good agreement with the measurement for most of the fire time and the difference observed in the 2 curves at the end of fire is again related to the temperature regime applied to the structure.

Over the whole structure the most deflected beam is the one between grid line 1 and grid line 2. This secondary beam is connected at both ends to primary beams, thus the total deflection for this beam includes the deflections of the primary beam supporting it. Figure 10 shows the deflection curve at mid-span of the joist. Again, the two patterns for the deflection temperature relationship can be observed. The difference between the model and the experiment in this case is more pronounced with a maximum deflection of $320 \mathrm{~mm}$ obtained from the calculation against $370 \mathrm{~mm}$ from the measurements. Here again, the uncertainty of the slab temperature during the test, especially in the transverse direction, is important as the ribs temperature play a very important role in the development of alternative load carrying 
mechanism in the transverse direction (by tensile membrane action). According to the temperature reached in the transverse direction, the ribs can alter or prevent the composite beam from further deflection especially at the end of the fire where the joist axial capacity is very low due to the large properties degradation of the steel at the 1 atter stage of fire.

Test 3 Joist deflection under increasing temperature

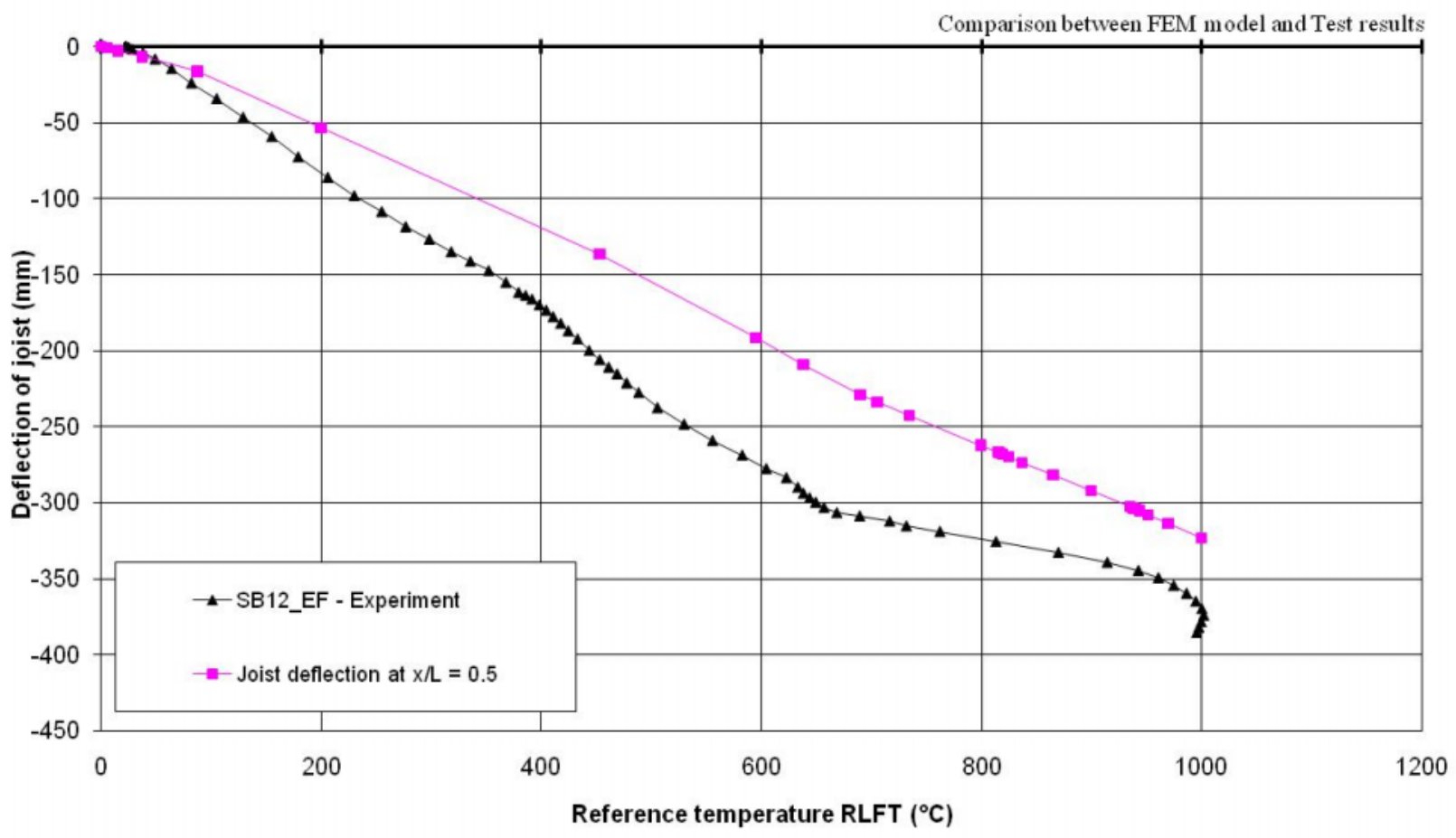

Figure 9 - Mid-span deflection of the heated secondary beam between grid 1 and 2

\section{Deflection of edge protected beams}

Two further comparisons of deflections are carried out for the edge protected beam. The fi rst edge beam is parallel to the secondary joist and is connected to columns at both ends. The comparison is shown in Figure 11, where the trends are generally comparable in both the numerical model and the experiment results. The maximum deflection obtain ed is of the order of $10 \mathrm{~mm}$ which is relatively low; this is because the successful measurements over this joist were obtained near the columns ends. 


\section{Test 3 Joist deflection under increasing temperature}

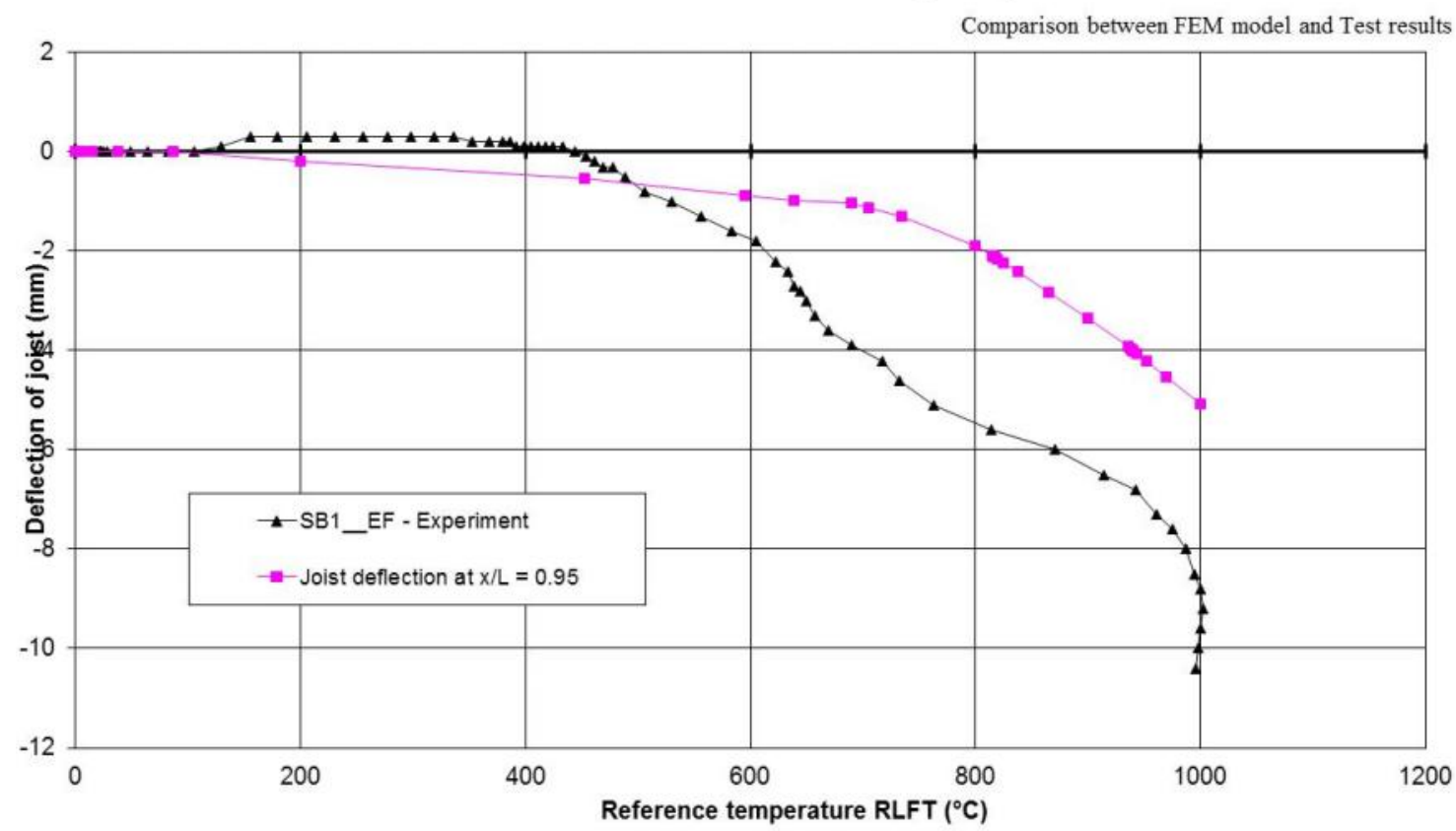

Figure 10 - Deflection near column of edge protected secondary beam on grid 1

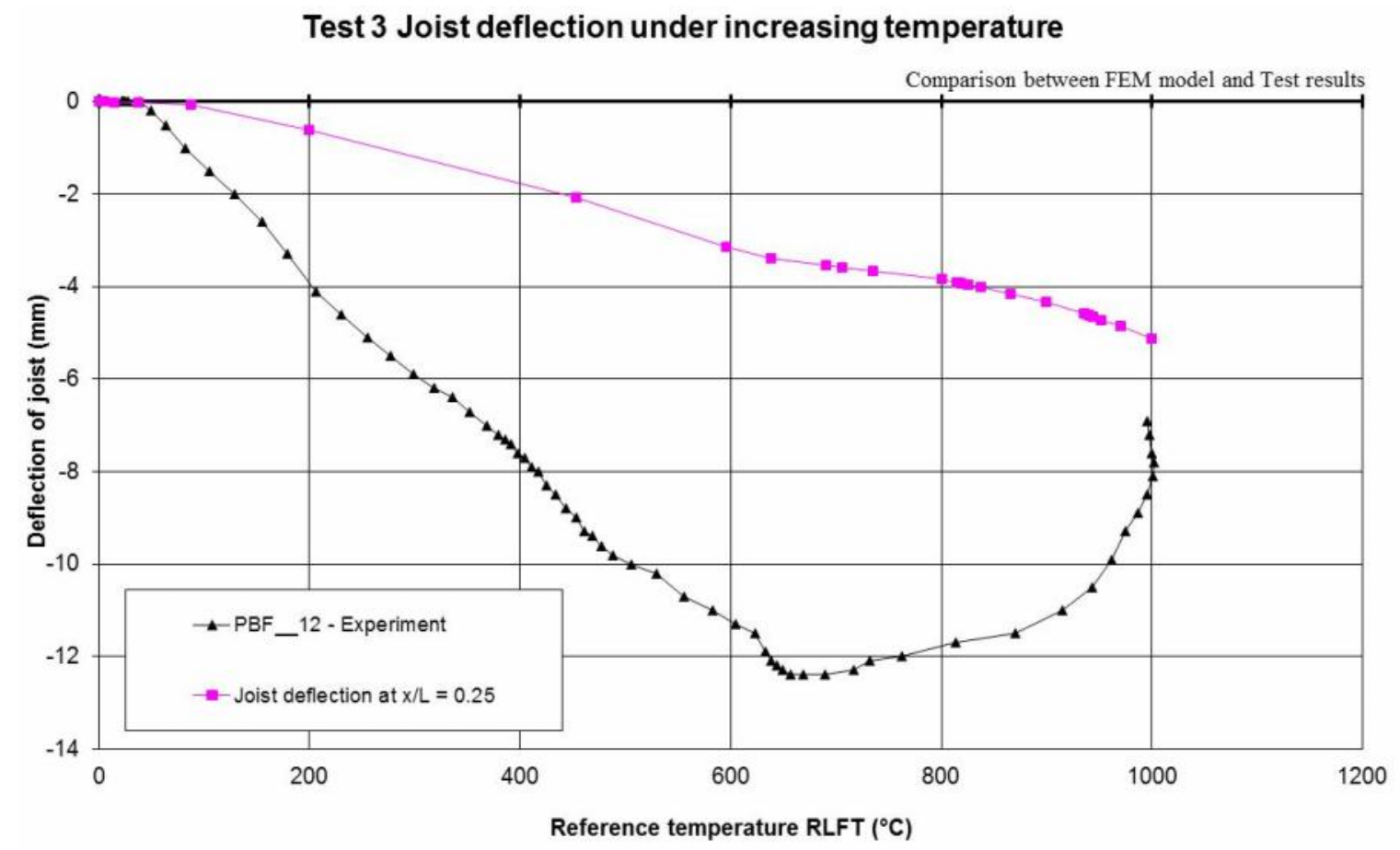

Figure 11 - Deflection of edge protected primary beam on grid $\mathrm{F}$ at $\mathrm{x} / \mathrm{L}=25 \%$ 
The final comparison is carried at $25 \%$ of the span of the edge beam parallel to the primary beams. Here it can be noticed that the trend is different between the model and the experiments. In the model the deflection is nearly linear from the start to the end (Figure 17). In the experiment the deflection increases from 0 to $640^{\circ} \mathrm{C}$ then reduces up to the end of the fire. The reason of such behaviour can be related to the fact that the edge composite beam has a relatively low torsional stiffness, thus during the last stage of the fire $\left(640^{\circ} \mathrm{C}\right.$ onward $)$ this beam rotates and displaces horizontally instead of vertically. Hence it has an increase of curvature in the horizontal plan which can easily dissipate the extra length obtained from the thermal expansion. It can be noticed that the final temperature measured over the primary protected edge beam was of the order of $250{ }^{\circ} \mathrm{C}$. This explains as well the low deflection values obtained over this beam (12mm at end of heating).

\section{$\underline{\text { Horizontal displacement of columns }}$}

A comparison was made for the horizontal displacement of the columns above the floor, where transducers were installed to measure the horizontal displacement s of columns. For column E1 connected to the heated primary beam, the measured displacements are compared with the numerical predictions as shown in Figure 13. The horizontal displacement is plotted against the reference temperature of the joist lower flan ge at mid-span. The positive sign indicates a horizontal displacement towards the outside of the building on the axis of the primary beam.

The comparison here shows that the order of magnitude of the displacement obtained from the numerical model is comparable with the test results. The model predicts $23 \mathrm{~mm}$ of column displacement outside the building against nearly $15 \mathrm{~mm}$ for the test. In the tests, the horizontal displacement reaches a maximum value between $500^{\circ} \mathrm{C}$ and $600^{\circ} \mathrm{C}$ then it displaces in the opposite direction (toward the inside of the building) till the end of the heating regime. In the numerical model the displacement is steady toward the outside of the building from the start to the end of the fire with a variation at $690^{\circ} \mathrm{C}$ corresponding to the change from step 1 to step 2 in the modelled heating temperature. The difference between the shape of the curves in the experiment and the numerical model can be related to the simplified heating regime adopted in the model. 


\section{Test 3: Column displacement under increasing temperature}

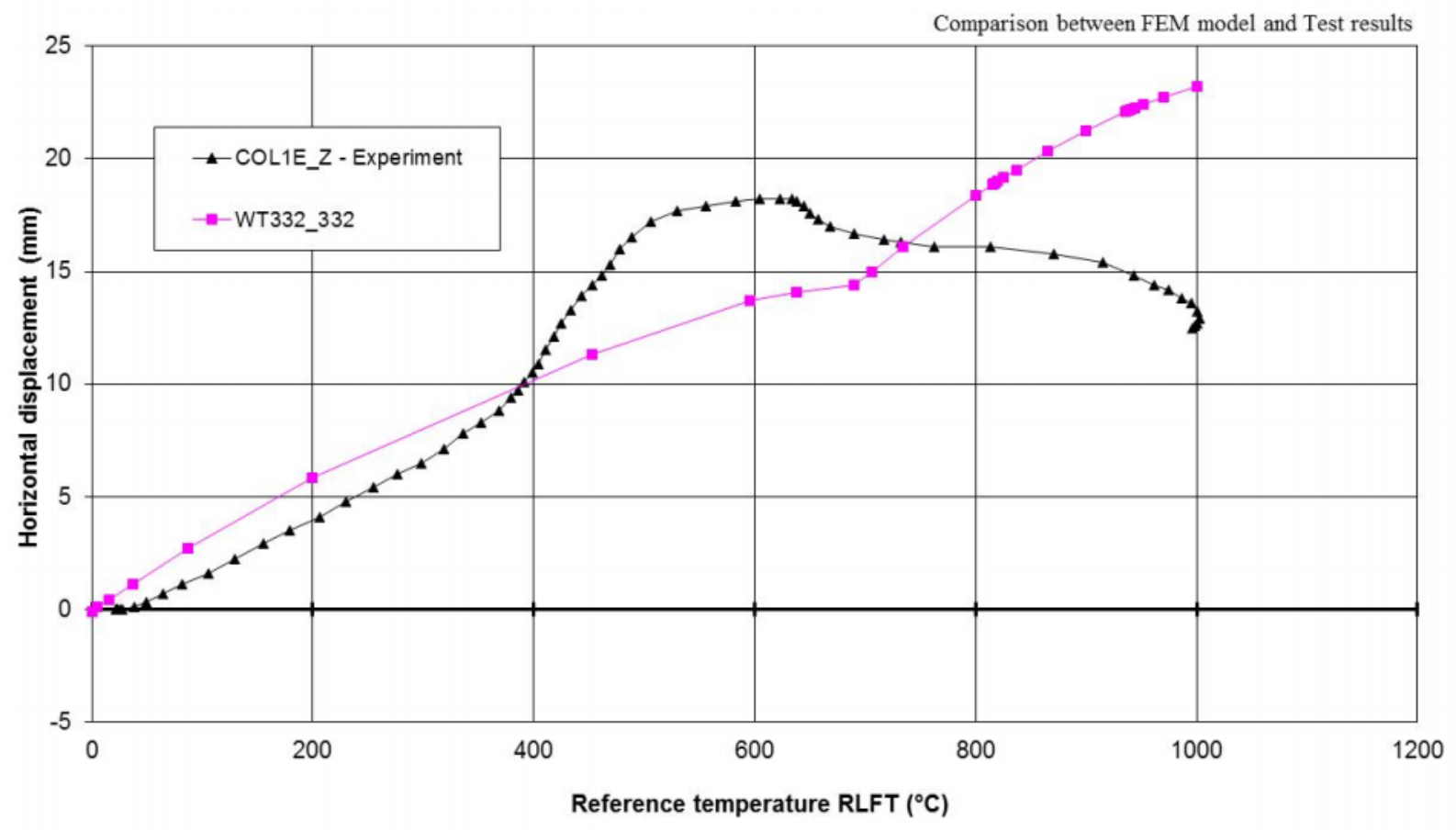

Figure 12 - Horizontal displacement of column E 1 in Y direction

Test 3: Column displacement under increasing temperature

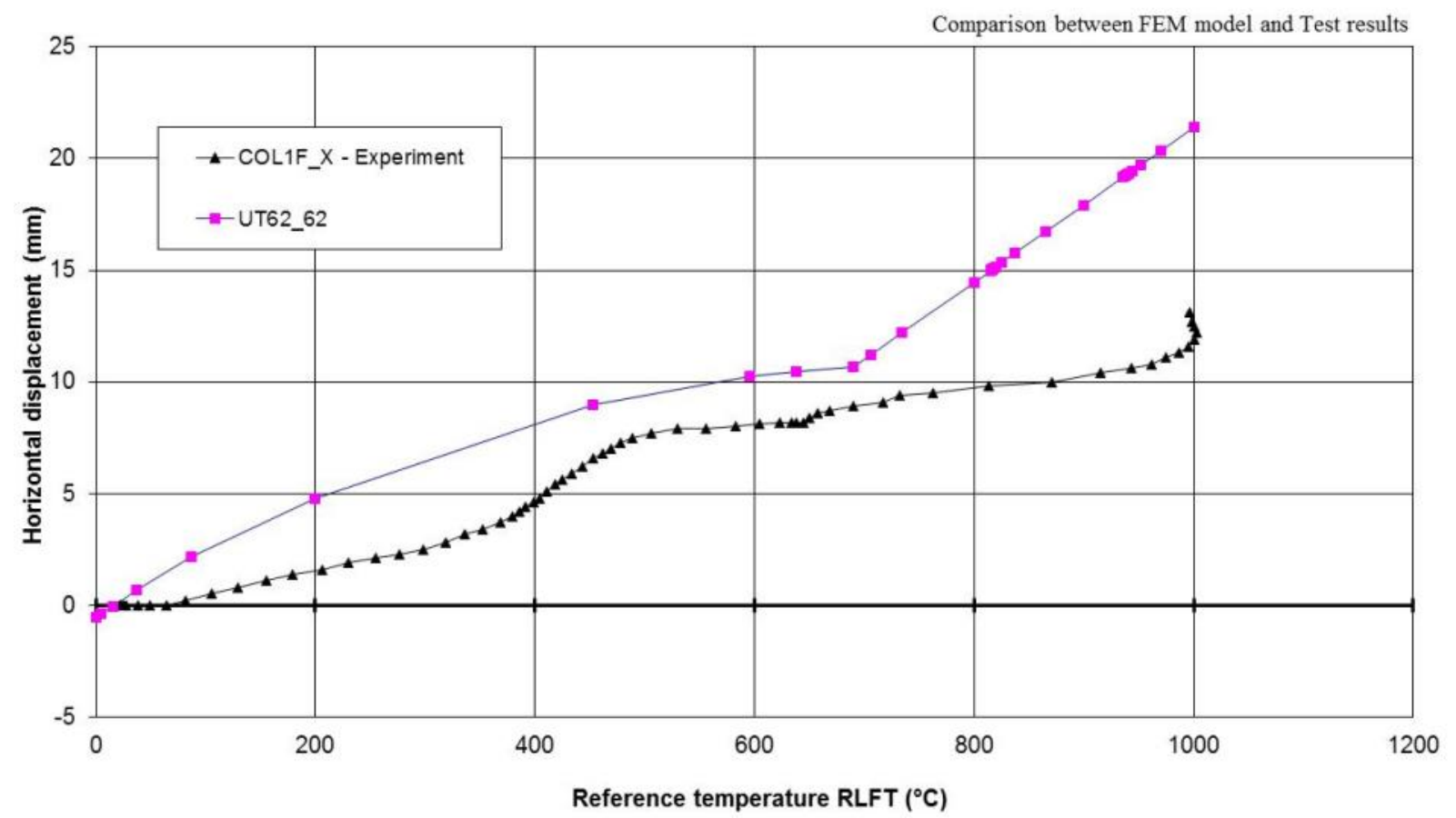

Figure 13 - Horizontal displacement of column F 1 in Y direction 
The following comparison is carried for the horizontal displacement of the corner column $(1 \mathrm{~F})$ in the direction of the secondary beam $(\mathrm{X})$. The shape of the curves in the model and the test are near to each other. The model predicts an increase in the horizontal displacement from 0 to $400^{\circ} \mathrm{C}$ then a plateau to $690^{\circ} \mathrm{C}$ followed by a linear increase to the end of the test. The magnitude of the horizontal displacement is $12 \mathrm{~mm}$ at end of fire in test against $22 \mathrm{~mm}$ in the model. The direction of the displacement is directed again outside the building on the axis of the edge protected secondary beam indicating that the floor is expanding the $\mathrm{x}$ and the $\mathrm{y}$ directions as obtained from the previous comparison. This important aspect of the behaviour of the slab is predicted in the numerical model and agrees with the test measurements.

Test 3: Column displacement under increasing temperature

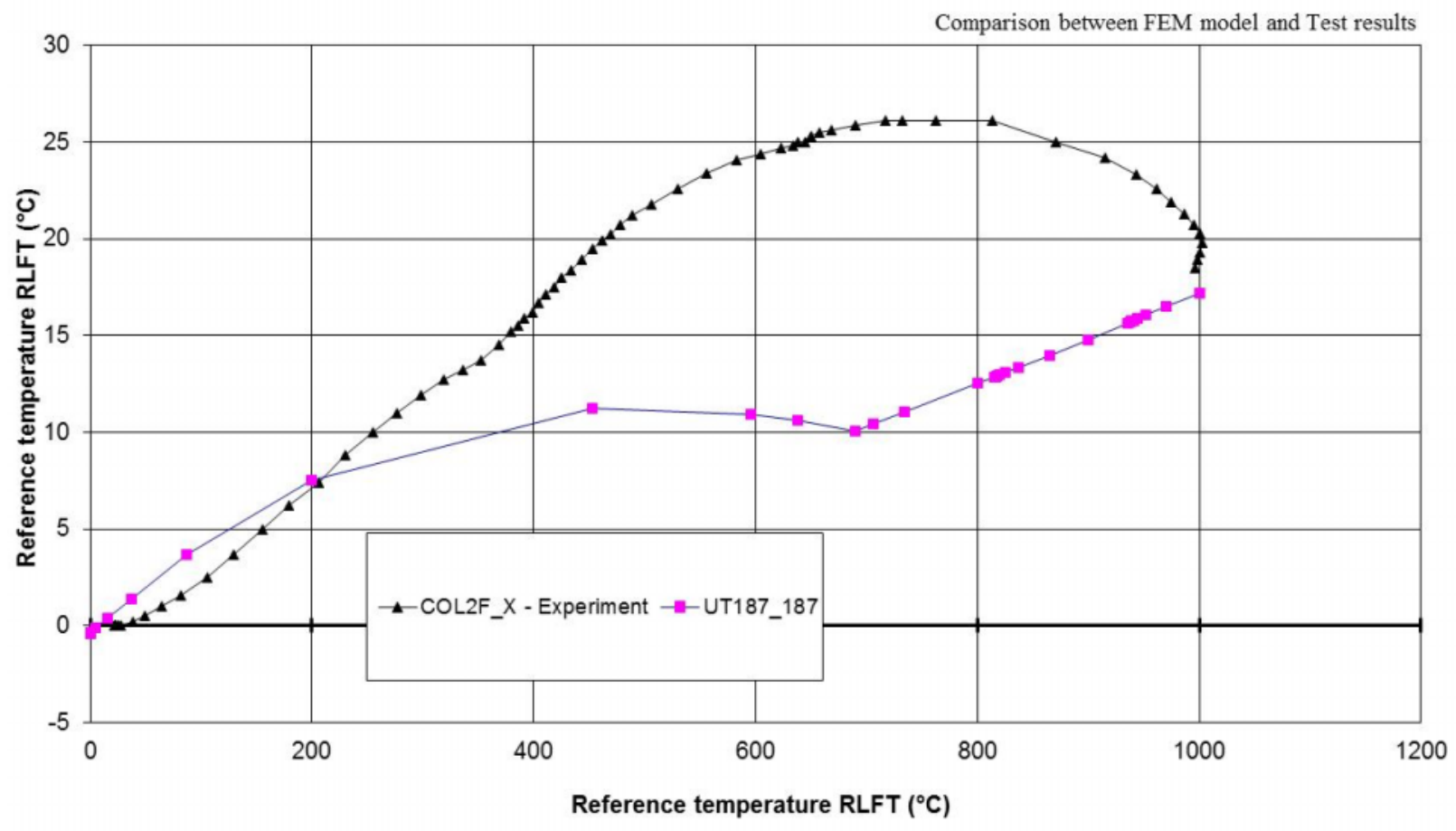

Figure 14 - Horizontal displacement of column F2 in X direction

The last comparison is carried for the external column F 2 connected the secondary beam SB2__EF. Again the model shows a positive displacement of the column due to the expansion of this heated beam. The test again shows an initial linear increase in the horizontal displacement which reaches a plateau at $650^{\circ} \mathrm{C}$ then the columns start moving to the inside of the building till the end of the fire while the model predicts again an initial non -linear increase followed by linear increase from $690^{\circ} \mathrm{C}$ to the end of the heating regime.

From the above comparisons, between the FE predictions and the obtained experimental results, it can be seen that the developed numerical model is in agreement with the test results, for different deflections and displacements and over the total time of the fire and for the 
different approaches used. The proposed model, described above, can predict with acceptable accuracy the global behaviour of the structure under fire conditions. The global structure deflection is dominated by the thermal expansion and the temperature reached in both the steel joints and the composite slab.

\section{Conclusions}

In this paper, a finite element model was developed to simulate a full-scale fire test carried by British Steel in the large building test facility at Cardington. The experimental work was dedicated to study the behaviour of the tested composite structure under a corner fire. The composite action between the slab and the beam was modelled by means of rigid elements coinciding with the shear stud locations. The connections between different steel members were modelled by imposing displacement constraints to the nodes of the members. Using the general purpose finite element program ABAQUS, a numerical model capabl e of predicting the behaviour of composite framed structures under fire condition was developed.

The obtained numerical results were compared with the experimental measurements at six different locations in the compartment, inside the heated zone and at the edge protected beams respectively. The comparisons showed a good agreement between the developed model and the test measurement for the total time of fire at different points of the unprotected beams. The horizontal displacements were also compared for three different columns and showed an agreement on the general trend of the floor expansion toward the outside of the building. The finite element model described in this paper has been developed with the aim of understanding local and global structural behaviour during fire and more details on the structural behaviour during this test is to be published in the near future.

\section{References}

1. ABAQUS (1994), "ABAQUS theory manual and user's manual, version 5.4", Hibbit, Karlsson and Sorensen Inc., Pawtucket, Rhode Island, USA

2. Bravery P.N.R., "Cardington large building test facility, Construction details for the first building", internal report British Steel plc., UK, 1995.

3. Eurocode 2, " Design of concrete structures - Part1-2 : General rules - Structural fire design", ENV 1992-1-2, 1995.

4. Eurocode 3, "Design of steel structures - Part1-2 : Fire resistance", ENV1993-1-2, 1995. 
5. Eurocode 4, "Design of composite steel and concrete structures - Part1-1 : General rules and rules for buildings", ENV 1994-1-1, 1994.

6. Gillie M., "An analysis of the behaviour of the first Cardington test using stress resultant shell elements", Proceedings of the First International Structures in Fire Workshop, 245-266, Copenhagen, Denmark, 2000.

7. Gillie M., Usmani A.S. and Rotter J.M., "A structural analysis of the Cardington British Steel corner test", Journal of Constructional Steel Research. Vol.58 No.4, 427442, 2002.

8. Khoury G.A., Grainger B.N. and Sullivan P.J.E., "Strain of Concrete during fire heating to $600^{\circ} \mathrm{C}$ under load", Magazine of Concrete Research Vol. 37, 195-215, 1985.

9. Kirby B.R., "Behaviour of a multi-story steel framed building subject to natural fires: Test3-restrained beam, deflection measurements", Document ref; S423/1/Part D1, British Steel plc., 1995.

10. O’Connor D.J., McAllister B., Munro J. and Bennett H.R., "Determination of the fire endurance of model concrete slabs using a plastic analysis methodology", The Structural Engineer, Volume 73, No. 19, October 1995.

11. O’Connor D.J., "Cardington Experimental Data", Pit project internal report, British steel, UK 1999.

12. Rose P.S., Bailey C.G., Burgess I.W. and Plank R.J., "The influence of floor slabs on the structural performance of the Cardington frame in fire", in Structures in the New Millenium, Balkema, Rotterdam, Netherland 1997.

13. Rose P.S., Burgess I.W., Plank R.J. and Bailey C.G., "The influence of floor slabs on the structural behaviour of composite frames in fire", Journal of Constructional Steel Research, Vol. 46, Nos 1-3, 1998.

14. Rotter, J.M., Sanad, A.M., Usmani, A.S. and Gillie, M., "Structural performance of redundant structures under local fires", Proc., Interflam '99, 8th International Fire Science and Engineering Conference, Edinburgh, 29 June - 1 July, Vol. 2, pp 1069 $1080,1999$.

15. Sanad, A.M., "Behaviour of Indeterminate beam under fire condition", Helwan Eng. Journal, Vol. 33, 2012. 
16. Sanad A.M., Lamont S., Usmani A.S and Rotter J.M., "Structural behaviour in fire compartment under different heating regimes - Part 1 (slab thermal gradient)", Fire Safety Journal, Vol. 35 No. 2- September 2000, 99-116.

17. Sanad A.M., Lamont S., Usmani A.S and Rotter J.M. "Structural behaviour in fire compartment under different heating regimes - Part 2 (slab mean temperature)", Fire Safety Journal, Vol. 35 No. 2- September 2000, 117-130.

18. Sanad A.M., Rotter J.M., Usmani A.S. and O'connor M.A., "Finite element modelling of fire tests on the Cardington composite building", Proceedings of Interflam'99, Interscience Communications Ltd. London, No.2, 1045-1056, 1999.

19. Sanad A.M., "British Steel Fire Test3: Reference ABAQUS model using grillage representation for slab", Technical report R00-MD10. University of Edinburgh, School of Civil and Environmental Engineering, February 2000, 25p.

20. Structural Fire Engineering Investigation of Broadgate Phase 8 Fire. The Steel Construction Institute, 1991.

21. Wang Y.C., Lennon T. and Moore D.B., "The behaviour of steel frames subject to fire”, Journal of Constructional Steel Research, Vol.35, 291-322, 1995.

22. Wang Y.C., "Tensile membrane action in slabs and its applicati on to the Cardington fire tests", Proceedings of the 2nd Cardington Conference, March, British Research Establishment, UK, 1996. 